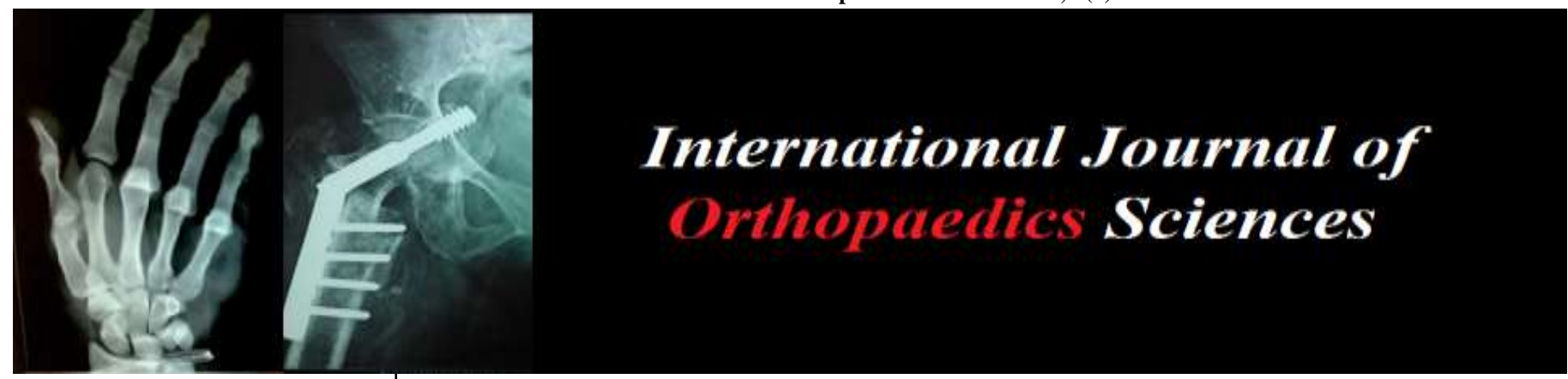

E-ISSN: 2395-1958

P-ISSN: 2706-6630

IJOS 2021; 7(2): 174-180

(C) 2021 IJOS

www.orthopaper.com

Received: 07-02-2021

Accepted: 11-03-2021

Ramesh Benguluri

Associate. Professor, DCMS,

Hyderabad, Telangana, India

Dr. C Rahul Reddy

Assistant Professor, DCMS,

Hyderabad, Telangana, India

Dr. B Venkatesh

DNB (Ortho), DCMS,

Hyderabad, Telangana, India

Dr. C Sham Sunder

Professor and Head of

Department of Orthopaedics,

DCMS, Hyderabad, Telangana, India
Corresponding Author: Ramesh Benguluri

Associate. Professor, DCMS,

Hyderabad, Telangana, India

\section{A comparative study between laprade and Larson's technique for posterolateral corner [PLC] Injury of knee}

\author{
Ramesh Benguluri, Dr. C Rahul Reddy, Dr. B Venkatesh and Dr. C Sham \\ Sunder
}

DOI: $\underline{\text { https://doi.org/10.22271/ortho.2021.v7.i2c.2628 }}$

\section{Abstract}

In the last few decades, injuries to the knee joint are common because of knee pivoting sports. The mechanism of injury to the PLC is due to direct varus stress, hyperextension, or twisting of the knee. These injuries are commonly associated with cruciate ligament tears, but PLC injury are usually overlooked or misdiagnosed. If Left untreated, it can cause chronic pain and residual instability. PLC reconstruction is normally advocated for grade 2 or 3 lesions, as it is superior to conservative treatment. This study is to compare larson's and laparde techinque. In Larson's technique there is reconstruction of the fibular collateral ligament and popliteo fibular ligament. In LaPrade technique popliteus graft is reinforced to the PLC. This is a prospective study conducted in 40 patients between April 2016 to January 2018 in Deccan Medical College and Hospitals, to compare the clinical outcome of Laprade and Larson's techniques in terms of best post-operative stability and function of an isolated PLC injury. Inclusion criteria:age ranging from 18 to 40 years, Posterio lateral corner injury, No previous surgery or damage in the affected knee or the contralateral knee. Exclusion criteria: Patients with medial collateral ligament injury, cruciate ligament injury, generalized ligamentous laxity and arthritis knee. Methods and analysis of results: it is randomized study between Larson's technique and Laprade's technique. Postoperative evaluation: is by Lysholm score, IKDC scores and Postoperative complications. In conclusion it revealed that both methods are significant, and equally good at postoperative outcomes.

Keywords: Larson's technique, laprade technique, posteriolateral corner injury of knee, lysholm score, IKDC Scores

\section{Introduction}

In the last few decades, injuries to the knee joint were common because of popular knee pivoting sports like soccer, and basketball. The Posteriolateral Corner (PLC) is an area of the knee that does not receive adequate research despite its contribution to stability of the knee. The PLC of the knee consists of important stabilizing structures that play a crucial role in Varus and rotational stability through all ranges of motion ${ }^{[1-3]}$. The 3 major static stabilizers of the PLC are the fibular collateral ligament (FCL), popliteus tendon (PLT), and popliteofibular ligament (PFL) ${ }^{[1]}$. These injuries rarely an isolated injury and are commonly associated with cruciate ligament tears ${ }^{[4-6]}$. PLC injury are usually overlooked or misdiagnose and if Left untreated, it can cause chronic pain and residual instability. PLC reconstruction is normally advocated for grade 2 or 3 PLC lesions, considering its superior outcomes compared with conservative treatment ${ }^{[7-13]}$. Animal and clinical studies have reported that grade III PLC injuries heal poorly without surgical intervention, resulting in Varus and rotational instability of the knee ${ }^{[14,15]}$. Chronic posteriolateral instability has also been shown to increase forces on the ACL and PCL, which can potentially lead to graft failure in the setting of multiligament injury $[16,17]$. Multiple PLC reconstruction techniques exist but none have proven to perform best. There has been great interest in two specific PLC techniques, Larsons and LaPrade. but the two techniques have never been compared against each other. Advantages of the Larson technique include: a relatively straight-forward procedure for reconstruction of the fibular collateral ligament (FCL) and popliteofibular ligament (PFL) that requires less time as compared to other techniques. 
The LaPrade technique benefits from the inclusion of popliteus tendon (PLT) graft which produces added reinforcement to the PLC.

\section{Anatomy}

The knee joint is a synovial hinge and tri axial joint consisting of three articulations, patella-femoral, medial and lateral tibiofemoral joint. It is characterized by presence of menisci because of which it is called as complex joint, The PLC is often called the "dark side" of the knee due to its complexity. The PLC consists of static and dynamic stabilizers. The static stabilizers include the posterolateral capsule, LCL, PFL and fabellofibular ligament. These three soft tissue structures stabilize the PLC at varying degrees of flexion and extension by resisting Varus gapping in combination with external rotation at the knee joint. The dynamic stabilizers are the biceps femoris, iliotibial band (ITB), and popliteus complex. The Cruciate Ligaments (ACL\&PCL) act as secondary stabilizers that resist rotation. The combination of all the primary and secondary structures help to stabilize the posterolateral corner of the knee.

\section{Mechanism of Injury}

Injuries to the PLC of the knee are commonly caused by sports injuries, falls, and vehicle accidents. A direct hit on the tibia when kneeis stretched may cause an isolated PLC injury. The PLC is primarily responsible for resisting Varus angulation and external rotation in addition to posterior displacement of the tibia. It is extremely important that the functionality of the PLC and tibiofibular joint be checked along with other clinical tests when diagnosing a knee injury. Injury occurs when the distal tibia is grounded or fixed and large amounts of angular force is exerted about the knee joint causing external rotation. This puts increased tensile stress on both the FCL and the PLT. These mechanisms of injury are commonly caused by athletic traumas, motor vehicle accidents, and falls ${ }^{[44]}$.

\section{Classification}

PLC injuries can be classified according to the damage to the PLC or the degree of posteriolateral instability. The following two classifications are most commonly used.

Bleday et al. ${ }^{[45]}$ and Fanelli and Larson ${ }^{[46]}$ classified the PLC injuries into.

Type A: Injuries involve the PFL and popliteus tendon. Clinically, only an increase in tibial external rotation is observed.
Type B: Injuries affect the PFL, popliteus tendon, and LCL. Mild Varus opening is observed in the Varus stress test at $30^{\circ}$ of knee flexion along with an increase in tibial external rotation.

Type C: Injuries involve the PFL, popliteus tendon, LCL, lateral capsular avulsion, and cruciate ligament disruption. Marked Varus instability is seen in type C injuries at $30^{\circ}$ of knee flexion.

The Hughston classification is based on the assessment of Varus instability or rotational instability under Varus stress force with the knee in full extension ${ }^{[47,48]}$.

Grade I represent minimal tearing of a ligament with no abnormal motion.

Grade II injury shows partial tearing with slight or moderate abnormal motion.

Grade III injury refers to complete tearing with marked abnormal movements.

\section{Clinical Evaluation}

Pain on the postero-lateral aspect of the knee is a typical symptom in the isolated acute PLC injuries. Patients with chronic injuries complain of broad pain such as medial, lateral joint line pain, and posterolateral pain ${ }^{[47,49]}$. Some may have common peroneal nerve injuries and present with paraesthesia or numbness as well. They often show functional instability when the knee is in extension, like knee giving way during activities like walking down and up the stairs ${ }^{[50]}$.

\section{Symptoms and signs}

Symptoms of the PLC 1 injury are pain, ecchymosis, oedema, and hardening, in standing position, they may present with a Varus alignment of the knees compared to their corresponding limb ${ }^{[51,52,53]}$, patient walks with slight knee flexion to prevent hyperextension and reduce pain associated with the lateral compartment. This altered gait pattern is a clear indicator of structural damage in the PLC ${ }^{[54,55]}$.

\section{Specialized Clinical Tests}

1. Posterolateral Drawer Test,

2. External Rotation Recurvatum

3. Reverse Pivot-Shift

4. Standing Apprehension Test

5. Dial Test

6. Varus Stress
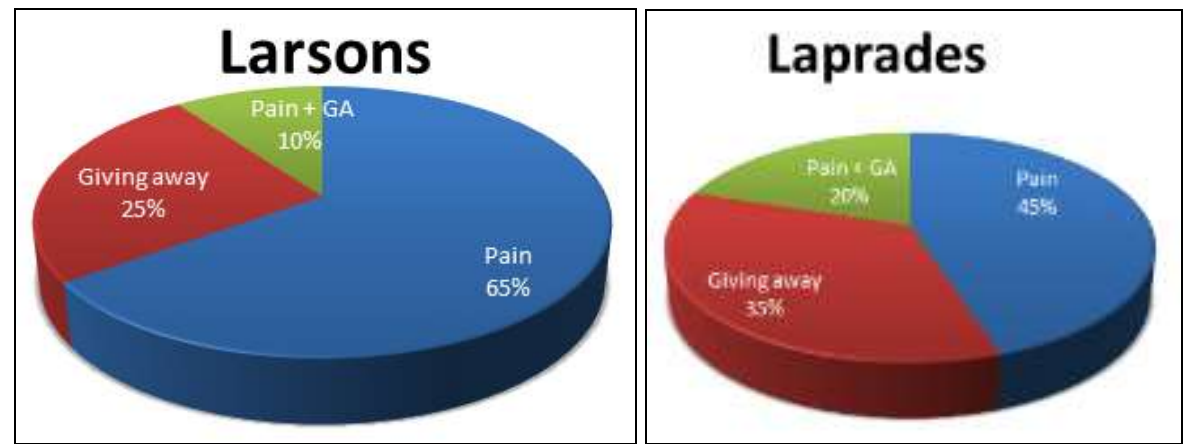

Graph 1: Presenting complaints

\section{Investigations}

\section{Plain radiography}

Plain radiography with anteroposterior (AP), lateral and axial views is taken to rule out fractures. The primary use of X-ray is to determine Varus misalignment/gapping in the lateral compartment 
Stress radiography are very helpful in the diagnosis of PLC injuries. LaPrade et al. ${ }^{[56]}$ assessed Varus stress radiographs with the knee at $20^{\circ}$ of flexion to provide objective measures of lateral compartment gapping. They reported that an increased opening of more than $4 \mathrm{~mm}$ may indicate a grade III PLC injury. In addition, the kneeling PCL stress radiograph also facilitates objective quantification of isolated or combined PLC injuries ${ }^{[57]}$.

Table 1: Instability Evaluation Using Stress Radiography

\begin{tabular}{|c|c|}
\hline Variable & Degres of injuiny \\
\hline \multicolumn{2}{|l|}{ Varus siress radiograph (mm) } \\
\hline 2.7 & Nensal kice of manor spaie \\
\hline 2.7 .4 & Compleie LCL leat \\
\hline$>4$ & Complete posterolateral injury \\
\hline \multicolumn{2}{|l|}{ PCL stress nadiograph (mm) } \\
\hline 4 & Variation in normal lknee of misor sprains \\
\hline $4-12$ & Isolatod PCL injuries \\
\hline$>12$ & Combined injuries of PCL \& PLC \\
\hline
\end{tabular}

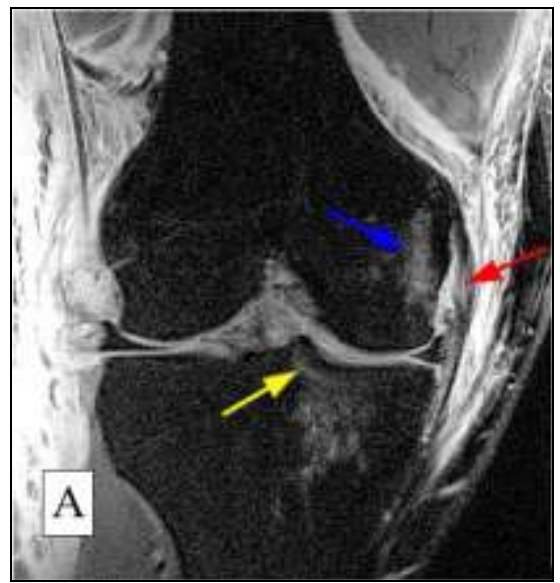

Magnetic resonance imaging (MRI)

MRI test can be beneficial when an injury of the posterolateral structures is difficult to diagnose clinically. Especially, the T2-weighted coronal oblique view is more useful in the evaluation of the posterolateral structures than the traditional coronal or sagittal view. MRI is also helpful to evaluate acute or subacute PLC injuries. Therefore, MRI should be taken within 12 weeks. It has been reported that only about $26 \%$ of the patients can be diagnosed when an MRI is taken after 12 weeks ${ }^{[58]}$. In addition, MRI's can identify alternative soft tissue structures that may have been injured in combination with the PLC.

Table 2: Classification of Posterolateral Instability Assessed by Varus or Rotational Instability

\begin{tabular}{|l|l|l|}
\hline Classification & Varus Rotational instability & PCL injury \\
\hline Grade I & $0-5 \mathrm{~mm}$ or $0-5$ & Intact PCL \\
\hline Grade II & $5-10 \mathrm{~mm}$ or $6-10$ & Intact PCL \\
\hline Grade III & $>10 \mathrm{~mm}$ or $>10$ (soft endpoint) & PCL rupture \\
\hline
\end{tabular}

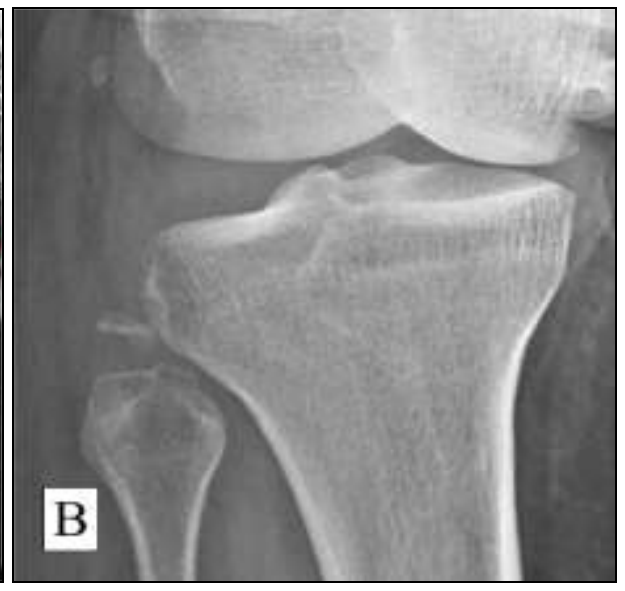

Fig 1: Radiograph imaging of an injured PLC. (A) MRI showing a strained FCL. (B) X-Ray showing lateral gapping between the lateral aspects of the distal femur and proximal tibia ${ }^{[59]}$

\section{Management}

\section{Non-Operative Treatment}

Grade I and grade II isolated PLC injuries can be treated with non-operative management. Appropriate rehabilitation and gait training may be helpful. The reported outcomes were $\operatorname{good}{ }^{[60]}$.

\section{Operative Treatment}

For grade III and grade II PLC injuries accompanied by other structural injuries, surgical management is recommended. The choice of treatment depends on the time of injury.

Acute PLC injury: In general, an acute injury is defined as an injury within 3 weeks of trauma. Acute injuries can be treated with direct repair or augmentation. If the grade of injury is severe or tissue is not vital enough, augmentation or reconstruction can be considered instead of primary repair. The hamstring tendon, biceps tendon, and ITB are candidates for allograft unlike the surgical improvements made for anterior and posterior reconstructions in the past decades, the posteriolateral corner has seen little advancement in comparison. Residual laxity, instability and graft failure still exist post operatively in present day outcomes ${ }^{[61-63]}$. In this study we compared two widely used PLC reconstruction techniques: Larson's and LaPrade. The reconstruction techniques and biomechanical evaluations of each technique are described below. 


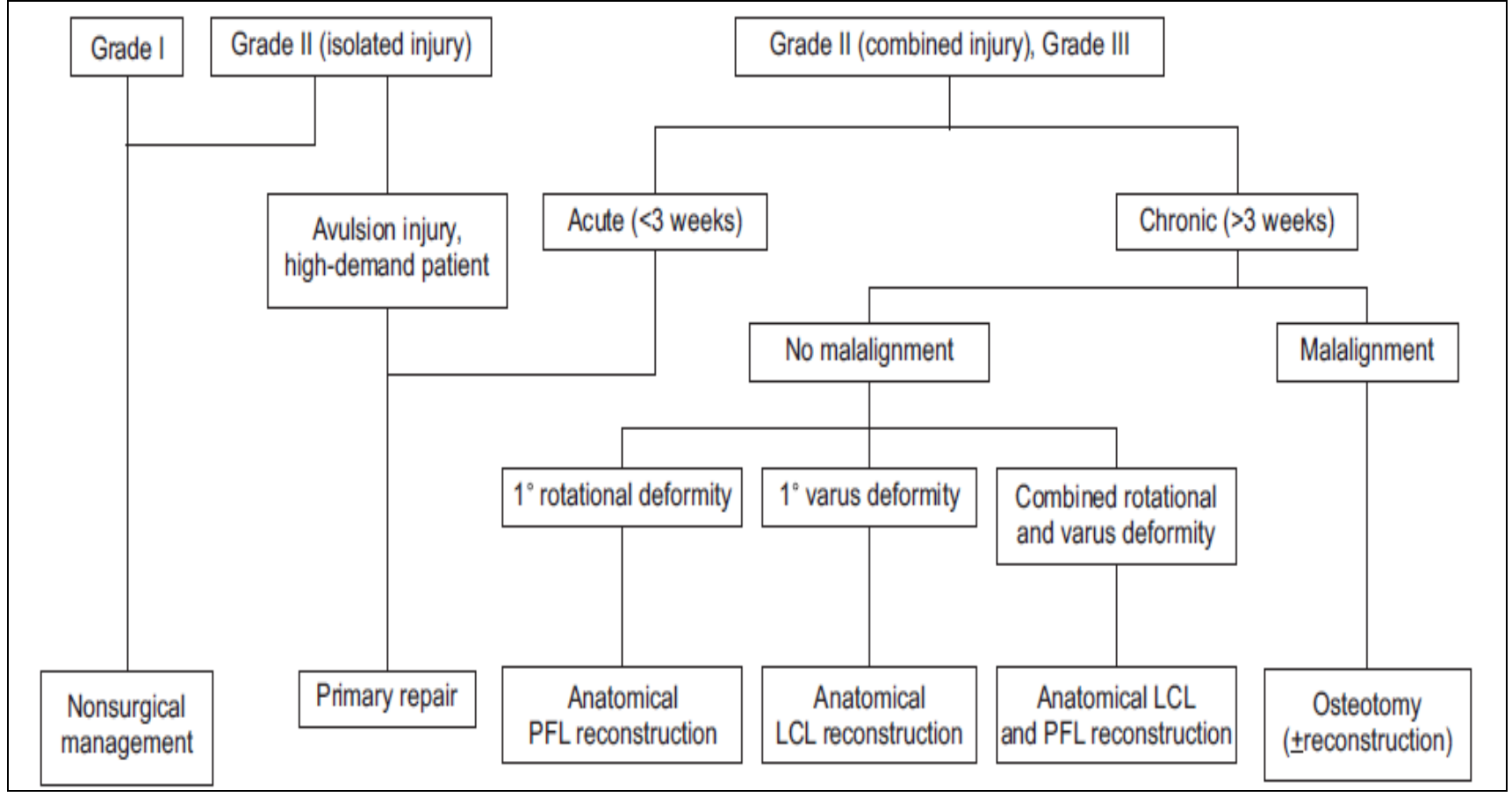

Fig 2: Algorithm of PLC injury treatment according to acute or chronic injuries

\section{Larson's Technique \\ Harvesting graft}

The graft for PLC is Semitendinosus (ST) tendon is harvested from the contralateral side using a smooth tendon stripper. The appropriate length of ST graft for PLC is $16-19 \mathrm{~cm}$, which typically reflects the distance between the femoral and fibular insertions of the PLC plus an additional $30 \mathrm{~mm}$, as both ends of the graft require at least $15 \mathrm{~mm}$ each, corresponding to the insertion into bone tunnels. One limb of the graft comprises PFL and the other comprises LCL. A baseball glove suture using Fiber Wire TM (Arthrex, Naples, FL) is used at the both ends of the graft, and one end of the popliteus tendon is connected to an Endobutton TM (Smith \& Nephew, Memphis, TN), then placed within antibiotic-soaked gauzes and set aside for fixation later.

\section{Incision}

A lateral incisionis given from lateral femoral epicondyle to the midpoint of Gerdy's tubercle and the fibular head. After femoral attachments of the LCL and popliteus tendon are exposed, they are taken off the femur. An incision is made on the biceps femoris muscle in line with this fiber so that the fibular head is well exposed. Anatomical insertions of the LCL and popliteus tendon at the lateral femoral condyle are drilled with 2.4-mm guide pins aimed toward the flare of the medial femoral epicondyle, followed by over drilling (typically $4-5 \mathrm{~mm}$ ). The peroneal nerve should be identified and retracted with the biceps muscle. To prepare the fibular tunnel, the starting point is set at the distal anterolateral portion of the fibular head, corresponding to the anatomical insertion of the LCL, and the guide pin should exit the proximal posteromedial portion of the fibular head, which corresponds to the insertion of the PFL.
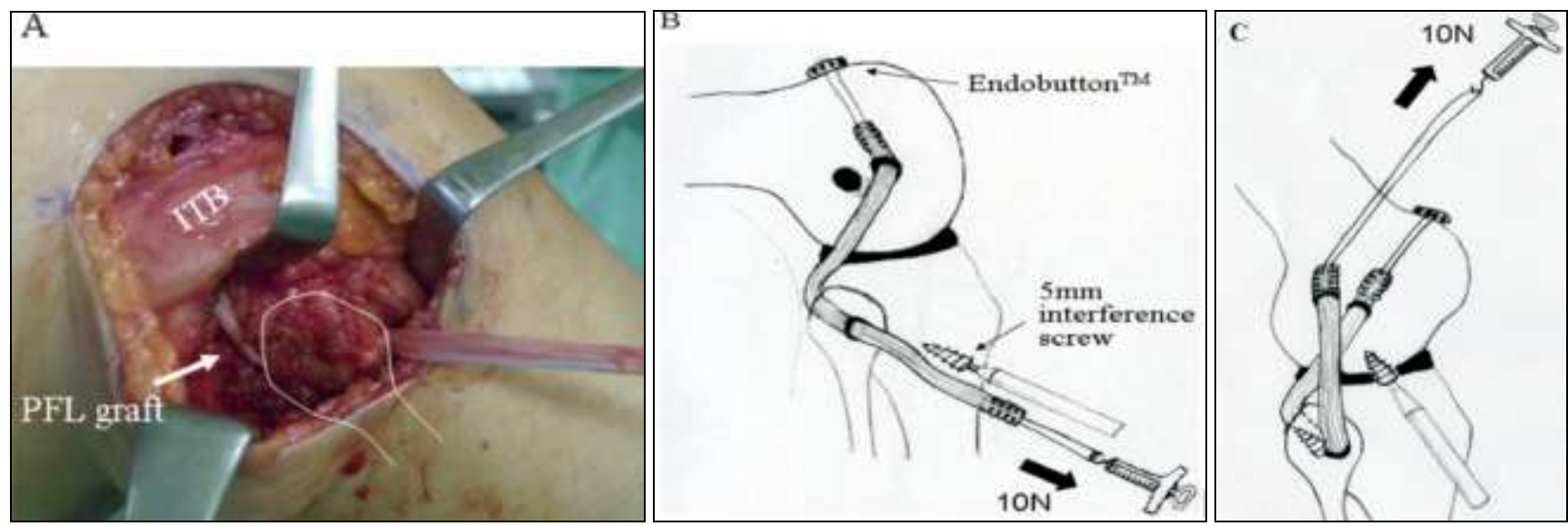

Fig 2: Semitendinosus tendon graft has been secured within the popliteus femoral tunnel using an Endobutton TM, delivered below the ITB, and passed through the trans fibular tunnel (A). The graft is fixed in the fibular tunnel with a metal interference screw under $10 \mathrm{~N}$ force of pretension at $90^{\circ}$ knee flexion (B)The graft end for the LCL is delivered under the biceps and ITB, and is passed into the femoral bone tunnel from the lateral epicondyle to medial cortex of the femur. The graft is then secured using an interference screw under $10 \mathrm{~N}$ force pretension with the knee in extension $(\mathrm{C})$.

The graft end for PFL connected to the Endobutton TM is delivered into the femoral bone tunnel and flipped on the cortex of the medial femoral condyle. The other end for LCL is then delivered under the iliotibial band and biceps femoris 
and is passed through the fibular tunnel from posterior to anterior. As the LCL graft end is strained manually, the knee is taken through several cycles of full flexion and extension. While the knee is held in $90^{\circ}$ of flexion and the tibia is in a neutral rotation, the graft is then secured in the fibular tunnel by use of a ligament tensioner. The graft end for the LCL is then delivered under the biceps and ITB, and is passed into the femoral bone tunnel from the lateral epicondyle to the medial cortex of the femur. After performing several cycles of full flexion and extension to provide pretension, graft fixation to the bone is accomplished using the 5-mm interference screw (TJ screw) with $10 \mathrm{~N}$ force applied to the graft at the knee in extension and neutral rotation by use of a ligament tensioner. Full flexion and extension are then verified, and improved knee stability is confirmed,

\section{Laprade Technique}

A $1.5-\mathrm{cm}$ medial incision is made $2 \mathrm{~cm}$ medial to the tibial anterior tubercle and around 4 finger breadths distal to the joint line. Semitendinosus and gracilis grafts are harvested and prepared with No.2 Ultrabraid (Smith \& Nephew, Andover, MA) Krackow stitches are applied. A curvilinear incision is made on the lateral side of the knee along the iliotibial band. The fibular nerve is identified and isolated. The space anterior to the lateral gastrocnemius and posterior to the biceps is dissected.

A transtibial tunnel is made from anterior to posterior, protecting the neurovascular structures, a guide pin is introduced at these locations, and a 7- to 8-mm drill is used to perforate the desired tunnel guided by the pin. The transfibular tunnel is first created with a guide pin and subsequently drilled to $7 \mathrm{~mm}$. It is oriented from anterior, lateral, and distal to posterior, medial, and proximal, aiming at reproducing the origin of the LCL at the fibular head. The tibial tunnel is measured, the semitendinosus tendon is mounted asymmetrically onto the Endo Button, the graft is passed from anterior to posterior at the 7-mm tibial tunnel and is secured anteriorly by suspensory fixation. The longest semitendinosus strand passed through the fibula will be directed toward the LCL femoral insertion along with the anterior gracilis strand and will reproduce LCL. The shortest semitendinosus strand exiting at the posterior part of the tibial tunnel will be directed toward the PT femoral insertion along with the posterior gracilis strand and will reproduce the PT. The tibia-fibula connecting part of the longest semitendinosus strand and the posterior gracilis strand will reproduce the PFL. Abone Bridge measuring approximately 5 to $10 \mathrm{~mm}$ will separate both tunnels. These femoral tunnels are reamed through the medial femoral cortex to facilitate graft passage. The grafts are routed through the third layer of the lateral side of the knee, deep to the iliotibial tract, lateral retinaculum, and biceps. The shortest and bulkiest semitendinosus strand emerging directly from the tibia and the posterior strand of the gracilis are inserted into the PT femoral insertion tunnel and secured with an8-mm interference screw with the knee flexed $60^{\circ}$ and in $5^{\circ}$ of internal rotation in relation to the foot-neutral position with $10 \mathrm{lb}$ of tension. The longest semitendinosus strands emerging from the fibula and the anterior gracilis strand will be inserted into the LCL femoral insertion tunnel and secured with an 8-mminterference screw with the knee flexed $30^{\circ}$, neutral rotation of the leg, valgus force, and $10 \mathrm{lb}$ of ten

Materials and Methods

This is a prospective study on 40 patients (20 in each group) operated between April 2016 to January 2018 conducted in the Department of Orthopaedics at Deccan College of Medical Sciences.

\section{Inclusion criteria}

1. Age ranging from 18 to 40 years.

2. Cases with only Posteriolateral corner injury.

3. No history of previous surgery of the cruciate ligament injury on affected knee.

\section{Exclusion criteria}

Patients with medial collateral ligament injury, posterior cruciate ligament injury, anterior cruciate ligament injury. Patient with osteoarthritis.

\section{Results}

For final end result, all patients were reviewed and analysed at the end of 6 months postoperatively. Results include preoperative, intraoperative findings and postoperative subjective assessment scores and examination findings, IKDC scoring scale, and range of motion, measured to the nearest 5 degrees by using a Goniometer.

\section{Scores for each}

The present study was undertaken to compare the short-term functional results of Larson posterio lateral corner reconstruction and Laprade technique of reconstruction, $32.5 \%$ of the patients were in 23-27 years age group. Mean age for Larson technique group is 27.39 and for laprade reconstruction group is 26.09. Patients were predominantly males. $85 \%$ in Larson group and $90 \%$ in laprade group. Right sided involvement in Larson group is 55\%of patients and $70 \%$ in Laprade group. Pain is the most common complaint reported. In the Larson group, patients presenting with only pain were $13(65 \%)$, patients presenting with only complaint of giving away were $5(25 \%)$ and patients presenting with complaint of pain associated with giving away were $2(10 \%)$. In the Laprade group, patients presenting with only complaint of pain were $9(45 \%)$, patients with only complaint of giving away were $7(35 \%)$ and patients with complaint of pain associated with giving away were 4(20\%).Most common complication among both the groups is knee pain $12.5 \%$ followed by infection $5 \%$. there were no sensory deficits reported Satisfactory results within each group in terms of Lysholm and IKDC scores when compared with preoperative and postoperative values. Post operatively 15 patients $(75 \%)$ had full range of motion $\left(0-140^{\circ}\right) .1$ patient $(5 \%)$ had $\left(0-130^{\circ}\right)$ range of motion, and 4 patients $(20 \%)$ had range of motion $(0-$ $\left.120^{0}\right)$.

Table 3: Lysholm score

\begin{tabular}{|c|c|c|}
\hline SCORE & Larson & Laprade \\
\hline Excellent & 0 & $4(20 \%)$ \\
\hline Good & $6(30 \%)$ & $9(45 \%)$ \\
\hline Fair & $10(50 \%)$ & $6(30 \%)$ \\
\hline Poor & $4(20 \%)$ & $1(5 \%)$ \\
\hline Total & $20(100 \%)$ & $20(100 \%)$ \\
\hline
\end{tabular}


Table 4: Complications

\begin{tabular}{|c|c|c|}
\hline Complications & Larsons & Laprades \\
\hline Infection & $2(33.3 \%)$ & 0 \\
\hline Knee pain & $3(50 \%)$ & $2(100 \%)$ \\
\hline Pain at teminal extension & $1(16.66 \%)$ & 0 \\
\hline Sensory deficits & 0 & 0 \\
\hline Total & $6(100 \%)$ & $2(100 \%)$ \\
\hline
\end{tabular}

\section{Conclusion}

Clear cut advantage of Laprade reconstruction technique is observed over Larson's technique in terms of postoperative outcomes or complications. Statistical analysis between both the groups revealed that both methods are significant, but there is no clear-cut superiority of one group over the other and that both methods are equally good at postoperative outcomes. We recommend that an anatomic posterolateral knee reconstruction be performed in patients with PLC injury to best improve functional and clinical outcomes. This study further needs to be evaluated. The validity of both techniques and to perform continued assessment for long-term results. Large scale study with long term follow up is required to corroborate findings of the study and to find out long term functional results in the two groups.

\section{References}

1. LaPrade RF, Ly TV, Wentorf FA, Engebretsen L. Theposterolateral attachments of the knee: a qualitative and quantitative morphologic analysis of the fibular collateral ligament, popliteus tendon, popliteofibular ligament, and lateral gastrocnemius tendon. Am J Sports Med 2003;31:854-860.

2. LaPrade RF. Force measurements on the fibular collateral ligament, popliteofibular ligament, and popliteus tendonto applied loads. Am J Sports Med 2004;32:16951701.

3. Gollehon DL, Torzilli PA, Warren RF. The role of theposterolateral and cruciate ligaments in the stability of thehuman knee. A biomechanical study. J Bone Joint Surg Am 1987;69:233-242.

4. LaPrade RF, Terry GC. Injuries to the posterolateral aspectof the knee. Association of anatomic injury patterns withclinical instability. Am J Sports Med 1997;25:433-438.

5. Noyes FR, Barber-Westin SD, Albright JC. An analysis ofthe causes of failure in 57 consecutive posterolateraloperative procedures. Am J Sports Med 2006;34:1419-1430.

6. LaPrade RF, Hamilton CD, Engebretsen L. Treatment ofacute and chronic combined anterior cruciate ligamentand posterolateral knee ligament injuries. Sports Med Arthrosc 1997;5:91-99.

7. Blackman AJ, Engasser WM, Krych AJ, Stuart MJ, Levy BA. Fibular head and tibial-based (2-tailed) posterolateral corner reconstruction. Sports Med Arthrosc 2015;23:4450 .

8. LaPrade RF, Johansen S, Wentorf FA, Engebretsen L, Esterberg JL, Tso A. An analysis of an anatomicalposterolateral knee reconstruction: An in vitro biomechanicalstudy and development of a surgical technique.Am J Sports Med 2004;32:1405-1414.

9. Miyatake S, Kondo E, Tsai TY et al. Biomechanicalcomparisons between 4-strand and modified Larson 2-strand procedures for reconstruction of the posterolateralcorner of the knee. Am J Sports Med 2011;39:1462-1469.

10. Moulton SG, Geeslin AG, LaPrade RF. A systematic review of the outcomes of posterolateral corner knee injuries,part 2: Surgical treatment of chronic injuries. Am JSports Med 2016;44:1616-1623.

11. Yoon KH, Bae DK, Ha JH, Park SW. Anatomic reconstructivesurgery for posterolateral instability of the knee.Arthroscopy 2006;22:159-165.

12. Bicos J, Arciero RA. Novel approach for reconstruction ofthe posterolateral corner using a free tendon graft technique.Sports Med Arthrosc 2006;14:28-36.

13. Fanelli GC, Larson RV. Practical management of posterolateralinstability of the knee. Arthroscopy 2002;18:1-8 (suppl).

14. LaPrade RF, Wentorf FA, Crum JA. Assessment of healingof grade III posterolateral corner injuries: an in vivo model. J Orthop Res 2004;22:970-975.

15. Griffith CJ, Wijdicks CA, Goerke U, Michaeli S, Ellermann J, LaPrade RF. Outcomes of untreatedposterolateral knee injuries: an in vivo canine model. KneeSurg Sports Traumatol Arthrosc 2011;19:1192-1197.

16. Harner CD, Vogrin TM, Hoher J, Ma CB, Woo SL. Biomechanical analysis of a posterior cruciate ligamentreconstruction. Deficiency of the posterolateral structuresas a cause of graft failure. Am J Sports Med 2000;28:32-39.

17. LaPrade RF, Muench C, Wentorf F, Lewis JL. The effect ofinjury to the posterolateral structures of the knee on forcein a posterior cruciate ligament graft: a biomechanicalstudy. Am J Sports Med 2002;30:233-238.

18. Black BS, Stannard JP. Repair versus reconstruction in acute posterolateral instability of the knee. Sports Med Arthrosc 2015;23:22-26.

19. LaPrade RF, Bollom TS. Anatomy and biomechanics of the posterolateral aspectof the knee. In: Fanelli GC, editor. Posterior cruciate ligament 2002, 23-46.

20. Terry GC, LaPrade RF. The biceps femoris complex at the knee: its anatomy and injury patterns associated with acute ALRI-AMRI. Am J Sports Med 1996;24:2-8.

21. Terry GC, LaPrade RF. The posterolateral aspect of the knee: anatomy and sur-gical approach. Am J Sports Med 1996;24:732-9.

22. LaPrade RF, Hamilton CD, Engebretsen L. Treatment of acute and chronic com-bined ACL and posterolateral knee ligament injuries. Sports Med Arthrosc Rev 1997;5:91-9.

23. LaPrade RF. Arthroscopic evaluation of the lateral compartment of knees with grade 3 posterolateral knee complex injuries. Am J Sports Med 1997;25(5):596-602.

24. Hughston JC, Jacobson KE. Chronic posterolateral rotatory instability of theknee. J Bone Joint Surg Am 1985;67(3):351-9.

25. Terry GC, Hughston JC, Norwood LA. The anatomy of the iliopatellar band andiliotibial tract. Am J Sports Med 1986;14:39-45.

26. Sutton JB. The nature of certain ligaments. J AnatPhysiol $1884 ; 18: 225-38$.

27. Watanabe Y, Moriya H, Takahashi K, Yamagata M, Sonoda M, Shimada Y et al. Functional anatomy of the posterolateral structures of the knee. Arthroscopy 1993;9(1):57-62. 
28. Stäubli HU, Birrer S. The popliteus tendon and its fascicles at the popliteal hiatus: gross anatomy and functional arthroscopic evaluation with and without anterior cruciate ligament deficiency. Arthroscopy 1990;6(3):209-20.

29. Gollehon DL, Torzilli PA, Warren RF. The role of posterolateral and cruciate ligaments in the stability of the human knee. A biomechanical study. J Bone Joint Surg Am 1987;69:233-242

30. Grood ES, Stowers SF, Noyes FR. Limits of movement in the human knee. effect of sectioning the posterior cruciate ligament and posterolateral structures. J Bone Joint Surg Am 1988;70:88-97

31. Markolf KL, Mensch JS, Amstutz H. Stiffness and laxity of the knee - the contributions of the supporting structures. J Bone Joint Surg Am 1976;58:583-594

32. Nielsen S, Helmig P. Posterior instability of the knee joint. An experimental study. Arch Orthop Trauma Surg. 1986;105:121-125

33. Nielsen S, Rasmussen O, Ovesen J, Andersen K. Rotator instabilty of cadaver knees after transection of collateral ligaments and capsule. Arch Orthop Trauma Surg 1984;103:165-169

34. Nielsen S, Helmig P. The static stabilizing function of the popliteal tendon in the knee. An experimental study. Arch Orthop Trauma Surg 1986;104:357-362.

35. Lipke JN, Janecki CJ, Nelson CL et al. The role of incompetence of the anterior cruciate and lateral ligaments in anterolateral and anteromedial instability. J Bone Joint Surg Am 1981;63:954-960

36. Noyes FR, Stowers SF, Grood ES, Cummings J, VanGinkel LA, Posterior subluxations of the medial and lateral tibiofemoral compartments. An invitro ligament sectioning study in cadaveric knees. Am J Sports Med 1993;21:407-414

37. Veltri DM, Deng X-H, Torzilli PA, Warren RF, Maynard MJ. The role of the cruciate and posterolateral ligaments in stability of the knee. Am J Sports Med 1995;23:436443

38. LaPrade F, Robert Ly V, Thuan. "The Posterolateral Attachments of theKnee, A Qualitative and Quantitative Morphologic Analysis of the Fibular Collateral Ligament, Popliteus Tendon, Popliteo_bular Ligament, and LateralGastrocnemius Tendon" Am J Sports Med. 2003, 854-860

39. Laprade F Robert, Morgan M, Patrick. "The Anatomy of the PosteriorAspect of the Knee, An Anatomic Study" J Bone Joint Surg 2007.

40. LaPrade F Robert, Bollom S, Timothy. "Mechanical Properties of the Posterolateral Structures of the Knee" Am J Sports Med 2005, 1386-1391

41. Sanchez IIR. Anthony, Sugalski, T. Matthew., "Anatomy and Biomechanics of the Lateral Side of the Knee" Sports Med Arthrosc Rev 2006(14)

42. Crespo, Bernardo, James W, Evan, Metsavaht, Leonardo, LaPrade F. Robert., "Injuries to Posterolateral Corner of the Knee: a Comprehensive Review from Anatomy to Surgical Treatment" Rev Bras Ortop 2014;50(4):363-70

43. LaPrade F, Robert, Moulton G, Samuel, Nitri, Marco, et al. "Clinically Relevant Anatomy and what Anatomic Reconstruction Means" Knee Surg Sports Traumatol Arthrosc 2015;(10):2950-9

44. Kim H Yoon, Purevsuren, Tserenchimed. Contribution of posterolateral corner structures to knee joint translational and rotational stabilities: A computational study" Journal of Engineering in Medicine 2013;227(9)968-975

45. Bleday RM, Fanelli GC, Giannotti BF, Edson CJ, Barrett TA. Instrumented measurement of the posterolateral
corner.Arthroscopy 1998;14:489-94.

46. Fanelli GC, Larson RV. Practical management of posterolateral instability of the knee.Arthroscopy. 2002;18(2 Suppl 1):1-8.

47. Hughston JC, Andrews JR, Cross MJ, Moschi A. Classification of knee ligament instabilities: part II. The lateral compartment. J Bone Joint Surg Am. 1976;58:173-9.

48. Ranawat A, Baker CL, 3rd, Henry S, Harner CD. Posterolateral corner injury of the knee: evaluation and management. J Am AcadOrthop Surg 2008;16:506-18.

49. 49. Hughston JC, Jacobson KE. Chronic posterolateral rotatory instability of the knee. J Bone Joint Surg Am. 1985;67:351-9.

50. Covey DC. Injuries of the posterolateral corner of the knee. J Bone Joint Surg Am 2001;83:106-18.

51. Shahane SA, Ibbotson C, Strachan R, Bickerstaff DR. The popliteofibular ligament: an anatomical study of the posterolateral corner of the knee. J Bone Joint Surg Br. 1999;81:636-42.

52. Bae WH, Ha JK, Kim JG. Treatment of posterolateral rotatory instability of the knee. J Korean Knee Soc. 2010;22:1-10.

53. Towne LC, Blazina ME, Marmor L, Lawrence JF. Lateral compartment syndrome of the knee. Clin OrthopRelat Res 1971;76:160-8.

54. Grood ES, Stowers SF, Noyes FR. Limits of movement in the human knee.Effect of sectioning the posterior cruciate ligament and posterolateral structures. J Bone Joint Surg Am 1988;70:88-97.

55. Veltri DM, Deng XH, Torzilli PA, Warren RF, Maynard MJ. The role of the cruciate and posterolateral ligaments in stability of the knee: a biomechanical study. Am J Sports Med 1995;23:436-43.

56. LaPrade RF, Heikes C, Bakker AJ, Jakobsen RB. The reproducibility and repeatability of Varus stress radiographs in the assessment of isolated fibular collateral ligament and grade-III posterolateral knee injuries: an in vitro biomechanical study. J Bone Joint Surg Am 2008;90:2069-76.

57. Jackman $\mathrm{T}$, LaPrade RF, Pontinen $\mathrm{T}$, Lender PA. Intraobserver andinterobserver reliability of the kneeling technique of stress radiography for the evaluation of posterior knee laxity. Am J Sports Med 2008;36:1571-6.

58. Pacheco RJ, Ayre CA, Bollen SR. Posterolateral corner injuries of the knee: a serious injury commonly missed. J Bone Joint Surg Br. 2011;93:194-7.

59. Sekiya JK, Haemmerle MJ, Stabile KJ, Vogrin TM, Harner CD. Biomechanical analysis of a combined double-bundle posterior cruciate ligament and posterolateral corner reconstruction. Am J Sports Med. 2005;33:360-9.

60. Geeslin AG, LaPrade RF. Outcomes of treatment of acute grade-III isolated and combined posterolateral knee injuries: a prospective case series and surgical technique. J Bone Joint Surg Am 2011;93:1672-83.

61. Yoon H Kyoung, Lee H Jung. "Comparison of Clinical Results of AnatomicPosterolateral Corner Reconstruction for Posterolateral Rotary Instability ofthe Knee With or Without Popliteal Tendon Reconstruction" Am J Sports Med 2011;39:2421

62. LaPrade F. Robert, Griffith. J. Chad., "Improving Outcomesfor Posterolateral Knee Injuries" Journal of Orthopedic Research 2014. DOI:10.1002/jor.22572

63. Jabara, Michael, Bradley Je_rey, Merrick, Michael. "Is Stability of the Proximal Tibiofibular Joint Important in the Multiligament-injured Knee?" Clin Orthop Relat Res. 2014;427:2691-2697. 